\title{
In vitro studies on the sensitivity pattern of Plasmodium falciparum to anti-malarial drugs and local herbal extracts
}

Grace I Olasehinde ${ }^{1 *}$, Olusola Ojurongbe ${ }^{2}$, Adegboyega O Adeyeba ${ }^{2}$, Obasola E Fagade $^{3}$, Neena Valecha ${ }^{4}$, Isaac $O$ Ayanda ${ }^{1}$, Adesola A Ajayi ${ }^{1}$ and Louis $O$ Egwari $^{1}$

\begin{abstract}
Background: The resistance of human malaria parasites to anti-malarial compounds has become considerable concern, particularly in view of the shortage of novel classes of anti-malarial drugs. One way to prevent resistance is by using new compounds that are not based on existing synthetic antimicrobial agents.

Results: Sensitivity of 100 Plasmodium falciparum isolates to chloroquine, quinine, amodiaquine, mefloquine, sulphadoxine/pyrimethamine, artemisinin, Momordica charantia ('Ejirin') Diospyros monbuttensis ('Egun eja') and Morinda lucida ('Oruwo') was determined using the in vitro microtest (Mark III) technique to determine the $\mathbf{I}_{50}$ of the drugs. All the isolates tested were sensitive to quinine, mefloquine and artesunate. Fifty-one percent of the isolates were resistant to chloroquine, $13 \%$ to amodiaquine and $5 \%$ to sulphadoxine/pyrimethamine. Highest resistance to chloroquine (68.9\%) was recorded among isolates from Yewa zone while highest resistance to amodiaquine (30\%) was observed in ljebu zone. Highest resistance to sulphadoxine/pyrimethamine was recorded in Yewa and Egba zones, respectively. A positive correlation was observed between the responses to artemisinin and mefloquine $(P<0.05)$, artemisinin and quinine $(P<0.05)$ and quinine and mefloquine $(P<0.05)$. A negative correlation was observed between the responses to chloroquine and mefloquine ( $>0.05)$. Highest anti-plasmodial activity was obtained with the ethanolic extract of $D$. monbuttensis $\left(I C_{50}=3.2 \mathrm{nM}\right)$ while the lowest was obtained from $M$. lucida $\left(\mathrm{IC}_{50}=25 \mathrm{nM}\right)$.
\end{abstract}

Conclusions: Natural products isolated from plants used in traditional medicine, which have potent anti-plasmodial action in vitro, represent potential sources of new anti-malarial drugs.

Keywords: In vitro, Sensitivity, Anti-malarial, Local herbs, Isolates

\section{Background}

The main cause of the worsening malaria situation in recent years has been the spread of drug-resistant parasites. This has led to rising malaria-associated mortality [1]. Anti-malarial drug resistance has emerged as one of the greatest challenges facing malaria control today and has also been implicated in the spread of malaria to new areas and re-emergence of malaria in areas where the disease had been eradicated [2,3]. Drug resistance has

\footnotetext{
* Correspondence: grace.olasehinde@covenantuniversity.edu.ng ${ }^{1}$ Department of Biological Sciences, Covenant University, Ota, Ogun State, Nigeria

Full list of author information is available at the end of the article
}

also played a significant role in the occurrence and severity of epidemics in some parts of the world. Population movement has introduced resistant parasites to areas previously free of drug resistance. Moreover, in recent years the situation has worsened due to malaria parasites becoming resistant to several anti-malarial drugs [4,5]. This resistance concerns numerous drugs, but is thought to be most serious with chloroquine (CQ), the cheapest and most widely used drug to treat malaria [6].

The use of plants for therapeutic purposes has long been in practice [7]. Medicinal plants have been used in virtually all cultures as a source of medicine [8] and for

\section{() Biomed Central}

(c) 2014 Olasehinde et al.; licensee BioMed Central Ltd. This is an Open Access article distributed under the terms of the Creative Commons Attribution License (http://creativecommons.org/licenses/by/2.0), which permits unrestricted use, distribution, and reproduction in any medium, provided the original work is properly credited. 
a long time natural products were the only sources of medication [9]. Several medicinal plants have been used locally to treat malaria infection. Medicinal plants, such as Momordica charantia (local name: Ejirin wewe), Momordica balsamina (local name: Ejirin), Ageratum conyzoides (local name: Imi Eshu), Diospyros monbuttensis (local name, Egun Eja), have been used to treat one ailment or the other in Africa, especially Nigeria [10-12].

The urgency generated by drug-resistant strains of malaria parasites has accelerated anti-malarial drug research over the last two decades. While synthetic pharmaceutical agents continue to dominate research, attention has increasingly been directed to natural products [13]. The success of quinine (QN) and artemisinin, isolated from Artemisia annua and its derivatives, for the treatment of resistant malaria has focused attention on plants as a source of anti-malarial drugs [14]. Moreover, plants have been the basic source of sophisticated traditional medicine systems for thousands of years and were instrumental in early pharmaceutical drug discovery and industry [15]. The world's poorest are the worst affected, and many treat themselves with traditional herbal medicines. These are often more available and affordable, and sometimes are perceived as more effective than conventional anti-malarial drugs [16].

Ethnobotanical information about anti-malarial plants used in traditional herbal medicine is essential for further evaluation of the efficacy of plant anti-malarial remedies, and efforts are now being directed towards discovery and development of new, chemically diverse anti-malarial agents [17]. Several rural dwellers depend on traditional herbal medicine for treatment of many infectious diseases [18]. The reputed efficacies of these plants have been experienced and passed on from one generation to the other.

About $75 \%$ of the population in Africa does not have direct access to conventional medicine for malaria treatment but they do have access to traditional medicine for treating fevers. Treatment with these remedies has suffered a number of deficiencies; identification of plant extracts may be insecure and the chemical content of extracts may vary considerably [11]. Natural products isolated from plants used in traditional medicine, which have potent anti-plasmodial action in vitro, represent potential sources of new anti-malarial drugs $[19,20]$. It had been advocated that direct crude drug formulation of the herbs following toxicological absolution (after it has been ascertained to be non-toxic) may not only produce dosage forms faster but will also lead to cheaper and more affordable drugs for the communities that need them [21]. This research was carried out in order to increase the database of plants whose extracts can be used in the treatment of malaria.

\section{Methods}

\section{Study area}

The study was carried out in Ogun State, south-western Nigeria. The state has a total land mass of 16,409.26 sq $\mathrm{km}$ and shares an international boundary with the Republic of Benin to the west and interstate boundaries with Oyo State to the north, Lagos and the Atlantic Ocean to the south and Ondo State to the east (Figure 1). For the purpose of this study, the state was grouped into zones based on the origin of the people, namely, Egba, Ijebu, Yewa/Awori and Remo. One major town from each of these zones (Abeokuta, Ijebu-Ode, Sango-Otta and Sagamu, in that order) was used as a study site. Abeokuta, the capital of Ogun State, lies between latitude $7010^{\prime} \mathrm{N}$ and $7015^{\prime} \mathrm{N}$ and longitudes $3017^{\prime} \mathrm{E}$ and $3026^{\prime} \mathrm{E}$. Ijebu-Ode lies between $6^{\circ} 49^{\prime} \mathrm{N}, 3^{\circ} 56^{\prime} \mathrm{E}$. Sango-Otta is situated within the tropical zone, lying between $60^{\circ}$ and $47^{\circ} \mathrm{N}$ of the Equator and $20.33^{\circ} \mathrm{E}$ and $30.18^{\circ} \mathrm{E}$ while Sagamu has its geographical coordinates as $6^{\circ} 51^{\prime} \mathrm{N}, 3^{\circ} 39^{\prime} \mathrm{E}$. Cultured isolates of Plasmodium falciparum, totalling 100 in all, were collected from all four towns.

\section{Sample collection}

State general hospitals located in the different zones were used as collection centres. Both in- and outpatients who presented with uncomplicated malaria in the hospitals were recruited for the research work. Blood of the patients was collected using heparin bottles. Subjects were screened according to exclusion/inclusion criteria. Samples used for the study were collected from subjects who had received QN and artemisinin derivatives within the previous seven days, 4-aminoquinolones within the previous 14 days, pyrimethamine or sulphonamides within 28 days or mefloquine within the previous 56 days of blood collection. Blood samples were collected for malaria screening by fingerprick and venipuncture in order to check the presence of asexual parasites in the peripheral smear of patients. Safety procedures were adopted in the collection of fingerprick samples by swabbing the area to be sampled with $70 \%$ alcohol and allowing it to dry before collection. The bleeding was done in the hospitals by clinicians and medical laboratory scientists. About $2-5 \mathrm{ml}$ of blood was drawn (venipuncture) using a sterile disposable syringe. The blood samples were collected between April 2008 and June 2009.

\section{Patients' characteristics}

A total of 4,066 subjects comprising 1,839 males and 2,227 females presenting with malaria in four different zones of Ogun State were recruited into the study. The total number of subjects recruited in Sango-Otta, Abeokuta, Ijebu-Ode and Sagamu were 1,120, 1,116, 995 and 835, 


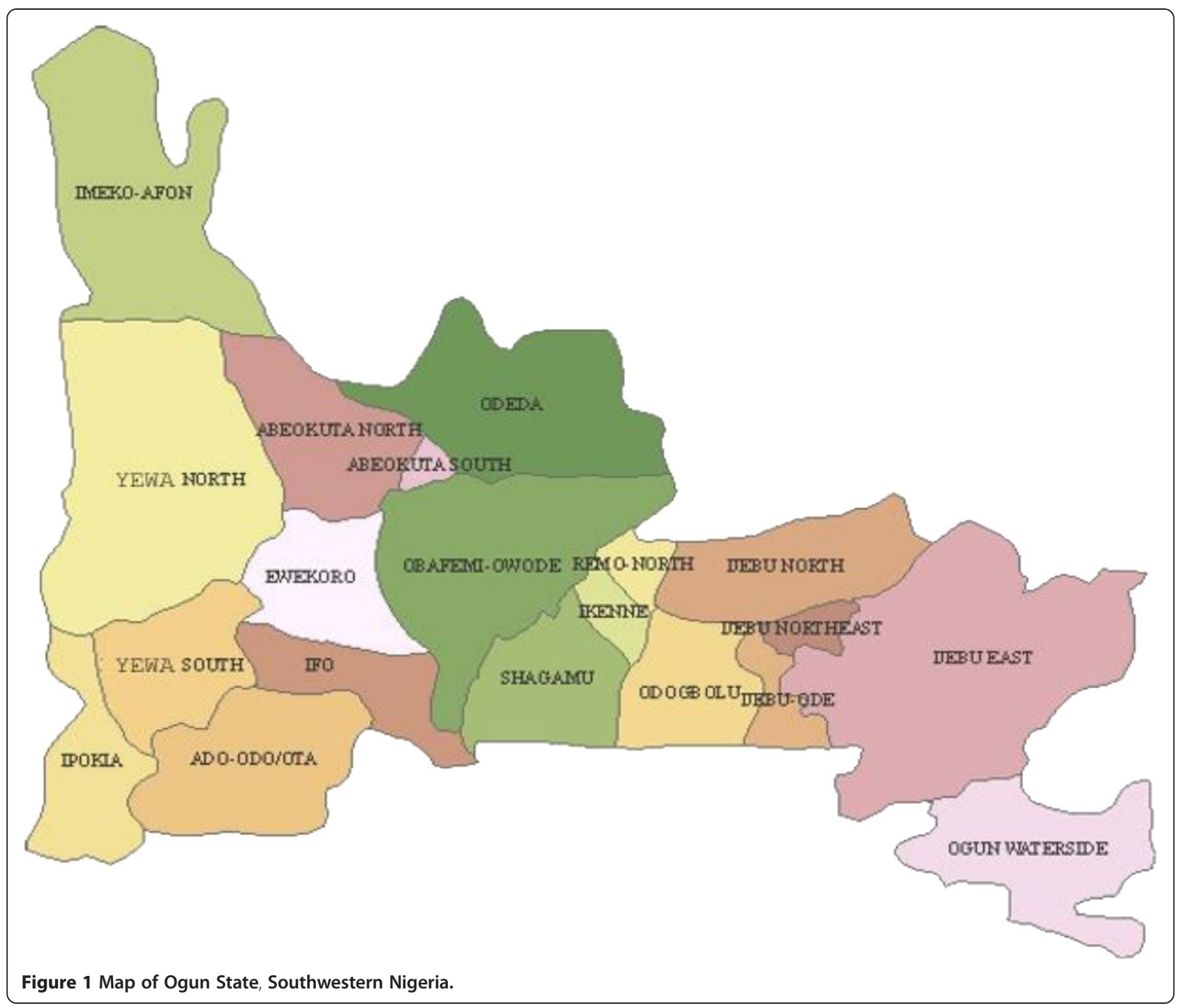

respectively. Children between one and 15 years, pregnant women and other adults were included in this study. This is because the majority of malaria cases occur in children under the age of 12 years; pregnant women are also especially vulnerable. The mean age was 19 years, with $93 \%$ less than 25 years old.

\section{Ethical consideration}

Scientific and ethical clearance for this work was obtained from the Nigerian Institute of Medical Research Institutional Review Board (NIMR-IRB) and Covenant University Ethics Committee. The Ogun State Ministry of Health (Hospitals Management Board) was also informed and clearance obtained for this study. Written informed consent was obtained from patients prior to recruitment into this study. Consent for children was provided by parents/guardians while some participants provided the assents.

\section{Microscopic examination}

Giemsa-stained thick and thin films were prepared for the microscopic examination of the malaria parasite. The thin films were fixed with methanol and all films were stained with $3 \%$ Giemsa stain of $\mathrm{pH} 7.0$ for $30 \mathrm{~min}$ as recommended by WHO [22]. Blood films were examined microscopically using 100X (oil immersion) objectives as described by Cheesbrough [23]. The thick films were used to determine the parasite densities while thin films were used to identify the parasite species and infective stages. Parasite density per microlitre of blood (parasitaemia) was estimated from the thick film, taking the number of leucocytes per microlitre of blood as 8,000 .

\section{Cryopreservation}

The infected blood was centrifuged at $959 \times \mathrm{g}$. The supernatant/plasma was removed and cells were suspended 
in equal volume of cryopreservative. The suspension was distributed into cryotubes and quickly frozen in cryofreezer at $-80^{\circ} \mathrm{C}$ and then transferred into liquid nitrogen $\left(-196^{\circ} \mathrm{C}\right)$. The cryopreservative was prepared by adding $28 \mathrm{ml}$ glycerol to $72 \mathrm{ml}$ of $4.2 \%$ Sorbitol in normal saline. The solution was sterilized by filtration through a Millipore filter of $0.22 \mu \mathrm{m}$ porosity.

\section{Cultivation of parasites}

The vial was taken out of the liquid nitrogen tank and thawed quickly in a $37^{\circ} \mathrm{C}$ water bath. The content was transferred to a centrifuge tube and centrifuged at $959 \times$ $\mathrm{g}$ for $10 \mathrm{~min}$. The supernatant was then removed and an equal volume of $3.5 \% \mathrm{NaCl}$ was added. The suspension was centrifuged again and the supernatant removed. The pellet was washed twice with complete medium supplemented with 15\% serum (Albumax). The parasites were cultured using a candle jar in RPMI 1640 medium supplemented with gentamicin solution at $0.01 \mathrm{mg} / \mathrm{mL}, 25$ mM HEPES buffer, $25 \mathrm{mM}$ NaHCO3, and 1\% Albumax II maintained in $5 \% \mathrm{CO}_{2}$ and incubated at $37^{\circ} \mathrm{C}$. The estimation of the parasitaemia, as well as parasite visualization before incubation, was done using Giemsa stained blood films on normal light microscopes.

\section{Preparation of plant extract}

Leaves of plants were used. The plants were identified in the Department of Pharmacognosy, Lagos University Teaching Hospital, Lagos. Ten grams of dried extract was dissolved in $50 \mathrm{ml}$ alcohol $(95 \%) 37^{\circ} \mathrm{C}$ for seven days at room temperature. The alcohol was allowed to evaporate at room temperature. Ten millilitres dimethyl sulphoxide (DMSO) was added to $10 \mathrm{mg}$ of each extract to make $1 \mathrm{mg} / \mathrm{ml}$.

\section{In vitro test}

The overall incidence of falciparum malaria as determined by microscopy in the study area was $62.7 \%$ $(2,250 / 4,066)$. Out of the $P$. falciparum samples collected, 100 isolates were successfully cultured and maintained in continuous culture for a minimum of three weeks. Drug samples were prepared in picomole/litre (pM) quantities according to WHO in vitro microtest procedure $[24,25]$. The assay was performed in duplicate in a 96-well microplate, according to WHO method (in vitro microtest (Mark III)), which is based on assessing the inhibition of schizont maturation. RPMI 1640 (Gibco BRL, Paisley, UK) was the culture medium used for cultivation of P. falciparum [26]. Dilution was prepared from the anti-malarial drugs. 1\% DMSO was used to prepare the drug stock. Also a control was set up where only the solvent was present in the well and the parasites were able to undergo schizogony in the control well. Stock solutions of chloroquine sulphate $(600 \mathrm{ng} / \mathrm{ml})$ and other anti-malarial drugs (amodiaquine $(\mathrm{AQ})=119$ $\mathrm{ng} / \mathrm{ml}$, mefloquine $(\mathrm{MQ})=265 \mathrm{ng} / \mathrm{ml}$, quinine $(\mathrm{QN})=$ $462 \mathrm{ng} / \mathrm{ml}$, artesunate $(\mathrm{AS})=360 \mathrm{ng} / \mathrm{ml}$, all prepared according to World Health Organisation's Standard Operating Procedures were prepared in sterile distilled water $(C Q$, $\mathrm{AQ}, \mathrm{MQ}$ and $\mathrm{Q}$ or ethanol (sulphadoxine/pyrimethamine (SP) and artemisinin) and used in two-fold dilutions with the culture medium in 96-well culture microplates (Nunc, Denmark) to obtain nine final dilutions (600 to $2.34 \mathrm{ng} / \mathrm{ml}$ for CQ) and appropriate dilution factor was determined for the other drugs and the crude plant extracts and the final concentrations prepared by serial dilution were $(125,62.5,31.25,15.6,7.8$, 3.9 and $1.95 \mu \mathrm{g} / \mathrm{ml})$. Negative controls treated by solvent and positive controls $(25 \mathrm{nmol} / \mathrm{L}$ chloroquine phosphate) were added to each set of experiments for the herbal extracts. Fifty $\mu$ which is the final volume per test well, from the parasitized blood mixture media was added to each well in plate and incubated in $\mathrm{CO}_{2}$ condition; $5 \% \mathrm{CO}_{2}$ at $37.5^{\circ} \mathrm{C}$ for $24-30$ hours. After incubation, contents of the wells were harvested and stained for $30 \mathrm{~min}$ in a $2 \%$ Giemsa solution $\mathrm{pH} 7.2$; after that, the developed schizonts were counted against the total asexual parasite count of 200. The count process was done in duplicate, and the data were analysed by using HN-NonLin V1.1 [27] to determine the $\mathrm{IC}_{50}$. The $\mathrm{IC}_{50}$ value is defined as the concentration of an anti-malarial drug that inhibits $50 \%$ of schizont maturation as compared with the development in drugfree control wells. $\mathrm{IC}_{99}$ gives a result that closely approximates a minimum inhibitory concentration (MIC). The $\mathrm{MIC}$ is generally defined as the lowest drug concentration that inhibits the development of rings to schizonts.

\section{Statistical analysis}

Data were analysed using Chi-square and ANOVA statistical tests. All the tests were performed at the 95\% confidence interval using SPSS version 15.0 software.

\section{Results}

In vitro anti-malarial drugs and local herbal extracts sensitivity tests were carried out and the $\mathrm{IC}_{50}$ and $\mathrm{IC}_{99}$ for each drug were determined. Table 1 shows the mean $\mathrm{IC}_{50}$ and $\mathrm{IC}_{99}$ values for $\mathrm{CQ}, \mathrm{AQ}, \mathrm{MQ}, \mathrm{QN}, \mathrm{SP}$ and As. Moreover, the in vitro threshold values for anti-malarials have been defined [28]. $\mathrm{IC}_{50}$ implies that $50 \%$ of the parasite could not mature to schizont stage at that drug concentration while $\mathrm{IC}_{99}$ implies that the anti-malarial drugs inhibited $99 \%$ of the parasites from maturing to schizont stage at that concentration.

All the selected isolates tested were sensitive to QN, MQ and AS while in vitro resistance was observed in CQ, AQ and SP (Table 2). Highest percentage of resistance to CQ $(69.8 \%)$ was recorded among isolates from 
Table 1 In vitro susceptibility of Plasmodium falciparum isolates to anti-malarial drugs

\begin{tabular}{llll}
\hline Drug & $\begin{array}{l}\mathbf{I C}_{\mathbf{5 0}} \text { mean } \\
(\mathbf{n M})\end{array}$ & $\begin{array}{l}\mathbf{I C}_{\mathbf{9 9}} \text { mean } \\
(\mathbf{n M})\end{array}$ & $\begin{array}{l}\text { Resistance } \\
\text { threshold (nM) }\end{array}$ \\
\hline Chloroquine (CQ) & 24.4 & 164.2 & $>160$ \\
Amodiaquine (AQ) & 6.3 & 32.4 & $>80$ \\
Artesunate (AS) & 3.2 & 7.8 & $>10.5$ \\
Mefloquine (MQ) & 42.1 & 60.8 & $>64.0$ \\
Sulphadoxine/ & 55.0 & 200 & $>300$ \\
Pyrimethamine (SP) & 0.7 & 2.5 & $>4.0$ \\
Quinine (Q) & 60.3 & 298.6 & $>300$ \\
\hline
\end{tabular}

Yewa zone while highest percentage of resistance to AQ (30\%) was observed in Ijebu zone. Highest percentage of resistance against SP (10\%) was recorded in Yewa and Egba zones. A positive correlation was observed between the responses to artemisinin and MQ $(\mathrm{P}<0.05)$, artemisinin and $\mathrm{Q}(\mathrm{P}<0.05), \mathrm{QN}$ and $\mathrm{MQ}(\mathrm{P}<0.05)$ (Table 2). A negative correlation was observed between the responses to $\mathrm{CQ}$ and MQ ( $>0.05)$.

The results of in vitro anti-malarial activity of the three herbal extracts tested -are as shown in Table 3. Of the selected three herbal extracts, the highest activity was obtained with extract of $D$. monbuttensis $\left(\mathrm{IC}_{50}=3.2\right.$ $\mathrm{nM}$ ) while the lowest was obtained from M. lucida $\left(\mathrm{IC}_{50}=25 \mathrm{nM}\right)$. In vitro resistance against $\mathrm{CQ}, \mathrm{AQ}$ and SP was observed among Nigerian isolates of P. falciparum tested. In the cross-sectional study, an $\mathrm{IC}_{50}$ of $24.4 \mathrm{nM}$ and $\mathrm{IC}_{99}$ of $164.2 \mathrm{nM}$ was recorded for CQ respectively Moreover, resistance threshold of isolates against sulphadoxine and pyrimethamine was $300 \mathrm{nM}$ and $4.0 \mathrm{nM}$, respectively. All the isolates tested against $\mathrm{MQ}, \mathrm{QN}$ and AS in this study were sensitive to the drugs. The sensitivity range observed in the current study was also within the range for sensitivity of isolates to the drug [28]. In vivo resistance against $C Q$, $\mathrm{AQ}, \mathrm{MQ}$ and SP has been reported by researchers in Nigeria $[29,30]$. The in vivo response of $P$. falciparum to anti-malarial drugs is modulated by a number of factors. These include the pharmacokinetic properties of anti-malarial drugs, innate and acquired immunity in the patient, as well as the complexity of infections in high transmission areas [29]. Several of these factors may
Table 3 In vitro susceptibility of Plasmodium falciparum isolates to local anti-malarial herbs

\begin{tabular}{ll}
\hline Herbal Drug & $\mathbf{I C}_{\mathbf{5 0}} \mathbf{n M}$ \\
\hline Momordica charantia (Ejirin) & 12.5 \\
Morinda lucida (Oruwo) & 25 \\
Diospyros monbuttensis (Eegun eja) & 3.2 \\
\hline
\end{tabular}

contribute to the range of variations in the clinical expression of CQ resistance and in vitro resistance patterns.

All the isolates tested in vitro against artemisinin were sensitive to the artesunate, a derivative of artemisinin. Bioavailability of artemisinin derivatives in vivo amongst other factors has been attributed to treatment failures [31]. AS, which is a derivative of artemisinin, was used for the in vitro drug testing in this study because it has been reported that dihydroartemisinin is unstable on drug plates and that artesunate is the most appropriate drug for in vitro drug assays due to its stability in predosed plates [32].

High resistance against $C Q$ and $A Q$ were observed among the isolates collected from Yewa and Ijebu zones while SP resistance was not observed in isolates from Remo zone. There was cross-resistance between CQ and $\mathrm{AQ}$ as some of the isolates that showed resistance to CQ also showed resistance to $\mathrm{AQ}$ in all the zones. Crossresistance between $\mathrm{CQ}$ and $\mathrm{AQ}$ has been reported both in vitro and in vivo. Pradines et al. [33] have observed cross-resistance of $\mathrm{CQ}$ and $\mathrm{AQ}$ in earlier studies. It has also been observed that parasites may quickly develop resistance to $A Q$ in areas where extensive $C Q$ resistance has been documented [34].

There is an increasing acceptance that the ideal approach to anti-malarial treatment is the use of a combination of two or more drugs, rather than a single antimalarial drug, preferably with an artemisinin derivative as one of the drugs $[28,35]$. AQ in combination with AS has been introduced as first-line treatment of malaria to replace CQ in Nigeria and other malaria-endemic countries of Africa [36]. Although the role of AS in this combination is to prevent the development of amodiaquine resistance, parasites may quickly develop resistance to $\mathrm{AQ}$ in areas where extensive $C Q$ resistance has been documented. In addition, little is known about the mechanism or

Table 2 Zone-wise resistance pattern of Plasmodium falciparum to anti-malarial drugs

\begin{tabular}{llllllll}
\hline Origin & Number of isolates cultured & CQ res (\%) & AQ res (\%) & As res (\%) & MQ res (\%) & SP res (\%) & Q res (\%) \\
\hline ljebu & 20 & $9(45)$ & $6(30)$ & $0(0)$ & $0(0)$ & $1(5)$ & $0(0)$ \\
Yewa & 43 & $30(69.8)$ & $4(9.3)$ & $0(0)$ & $0(0)$ & $2(10)$ & $0(0)$ \\
Egba & 25 & $5(20)$ & $1(4)$ & $0(0)$ & $0(0)$ & $2(10)$ & $0(0)$ \\
Remo & 12 & $7(58.3)$ & $2(16.7)$ & $0(0)$ & $0(0)$ & $0(0)$ & $0(0)$ \\
Total & $\mathbf{1 0 0}$ & $\mathbf{5 1 ( 5 1 )}$ & $\mathbf{1 3 ( 1 3 )}$ & $\mathbf{0 ( 0 )}$ & $\mathbf{0 ( 0 )}$ & $\mathbf{5 ( 5 )}$ & $\mathbf{0}(\mathbf{0})$ \\
\hline
\end{tabular}

$\mathrm{CQ}$ - chloroquine; $\mathrm{AQ}$ - amodiaquine; As - artesunate; $\mathrm{MQ}$ - mefloquine; SP - sulphadoxine/pyrimethamine; $\mathrm{Q}$ - quinine; res - resistance. 
epidemiology of AQ resistance. Resistant parasites may then likely recrudesce under the selective force of the second drug in the combination and be transmitted to mosquitoes [37]. Therefore, the possibility of increasing selection of AQ-resistant parasites with the increasing use of AQ in combination with AQ in Nigeria cannot be ruled out. Reduced in vitro susceptibility is not synonymous with diminished therapeutic effectiveness, but it is the probable first step of an alarming cascade and definitely pleads for increased vigilance and a coordinated and rapid deployment of drug combinations.

Developing countries, where malaria is one of the most prevalent diseases, still rely on traditional medicine as a source for the treatment of this disease. While synthetic pharmaceutical agents continue to dominate research, increasing attention has been directed to natural products [38]. The success of artemisinin, isolated from Artemisia annua, and its derivatives for the treatment of resistant malaria has focused attention on plants as a source of anti-malarial drugs [14]. In this study, three crude organic extracts obtained from medicinal plants used in Nigerian folk medicine for the treatment of fever and malaria were tested in vitro against $P$. falciparum. Diospyros monbuttensis showed appreciable inhibition to the parasites at all the concentrations used and an $\mathrm{IC}_{50}$ of $3.2 \mathrm{nM}$ in the study. Diospyros monbuttensis, which is locally used for the treatment of fevers, headaches and stomach disorders $[10,11]$, has not been widely studied. This study represents the first conducted for antimalarial activity of crude extracts of D. monbuttensis. The results confirm that these plants, which are used in traditional medicine against malaria, may possess in vitro and significant anti-malarial potential and justify their use in traditional medicine. This observation suggests that the active constituents in the extract may be cytotoxic for $P$. falciparum trophozoites, thereby inhibiting their development to the schizont stage.

An $\mathrm{IC}_{50}$ observed for $M$. charantia in this study was $12.5 \mathrm{nM}$. These observations suggest that the active constituents in the extract might also be cytotoxic for $P$. falciparum trophozoites, thereby inhibiting their development to the schizont stage. The anti-malarial activity of M. charantia has been previously reported [38]. They found that the aqueous extract of $M$. charantia leaves showed $\mathrm{IC}_{50}$ values less than $100 \mu \mathrm{g} / \mathrm{ml}$ which is in agreement with the observations in this study; the methanolic extract showed moderate activity with $\mathrm{IC}_{50}=12.5 \mathrm{nM}$. Morinda lucida also exhibited anti-malarial activity in this study. The $\mathrm{IC}_{50}$ of 25 $\mathrm{nM}$ observed in this study is comparable with other studies. Also for M. lucida, dose-dependent inhibitory outcomes were marked. Awe and Makinde [10], reported the dosedependent and seasonal variation in the activity of $M$. lucida using both in vitro and in vivo techniques. Morinda lucida was reported to contain anthraquinones, which showed in vitro activity against $P$. falciparum and also possess antifungal properties. Morinda lucida is used locally in the treatment of yellow fever and jaundice [39].

\section{Conclusions}

In vivo studies on these medicinal plants are necessary and should seek to determine toxicity of the active constituents, their side effects, serum-attainable levels, pharmacokinetic properties and diffusion in different body sites. Additional pharmacokinetic investigations are therefore advisable to identify host-related factors, such as poor absorption, accelerated gastrointestinal passage of the test drug, or metabolic peculiarities of some patients, which might lead to a faster-than-normal inactivation or elimination of the test drug.

\section{Competing interests}

The authors declare that there are no competing interests.

\section{Authors' contributions}

OGI conceived the study and carried out the in vitro sensitivity studies; OO participated in the design; $\mathrm{AOA}$ participated in the design and the analysis of the in vitro sensitivity studies; FEO participated in the design and helped to draft the manuscript; VN participated in the analysis of the in vitro sensitivity studies; ELO participated in the design and analysis of the in vitro sensitivity studies; AAA participated in the collection and extraction of plants; $\mathrm{AOI}$ participated in the collection of plants and statistical analysis. All authors read and approved the final manuscript.

\section{Acknowledgement}

Authors will like to acknowledge OWSD and NIMR, India for providing funds and facilities for the research.

\section{Author details}

${ }^{1}$ Department of Biological Sciences, Covenant University, Ota, Ogun State, Nigeria. ${ }^{2}$ Department of Medical Parasitology, LAUTECH Teaching Hospital, Osogbo, Osun State, Nigeria. ${ }^{3}$ Department of Botany, University of Ibadan, Ibadan, Oyo State, Nigeria. ${ }^{4}$ National Institute of Malaria Research, New Delhi, India.

Received: 12 February 2013 Accepted: 29 September 2013

Published: 20 February 2014

\section{References}

1. McCollum AM, Poe AC, Hamel M, Huber C, Zhou Z, Shi PY, Ouma P, Vulule J, Bloland P, Slutsker L, Barnwell JW, Udhayakumar V, Escalante AA: Antifolate resistance in Plasmodium falciparum: multiple origins and identification of novel dhfr alleles. J Infect Dis 2006, 194:189-197.

2. Bloland BP: Drug resistance in malaria. Geneva: World Health Organization; 2001. WHO/CDS/CSR/DRS/2001.4:1.

3. Noedl H, Se Y, Schaecher K, Smith BL, Socheat D, Fukuda MM: Evidence of artemisinin-resistant malaria in western Cambodia. N Eng J Med 2008, 359:2619-2620.

4. Phyo AP, Nkhoma S, Stepniewska K, Ashley EA, Nair S, McGready R, ler Moo C, Al-Saai S, Dondorp AM, Lwin KM, Singhasivanon P, Day NP, White NJ, Anderson TJ, Nosten F: Emergence of artemisinin-resistant malaria on the western border of Thailand: a longitudinal study. Lancet 2012, 379:1960-1966.

5. Ursos LM, Roepe PD: Chloroquine resistance in the malarial parasite, Plasmodium falciparum. Med Res Rev 2002, 22:465-491.

6. Sucharit S, Surathin K, Tumrasvin W, Sucharit P: Chloroquine resistant Plasmodium falciparum in Thailand: susceptibility of Anopheles. J Med Ass Thai 1977, 60:648-654.

7. Ogbonna DN, Sokari TG, Agomuoh AA: Antimalarial activities of some selected traditional herbs from Southeastern Nigeria against Plasmodium species. Res J Parasitol 2008, 3:25-31. 
8. Hoareau L, Dasilva EJ: Medicinal plants: a re-emerging health aid. Elec J Biotech 1999, 2:56-69.

9. Bourdy M, Willcox L, Ginsburg H, Rasoanaivo P, Graz B, Deharo E: Ethnopharmacology and malaria: New hypothetical leads or old efficient antimalarials? Intl J Parasitol 2008, 38:33-41.

10. Awe SO, Makinde JM: Evaluation of the antimalarial activity of Morinda lucida using both in vivo and in vitro techniques. W Afr J Pharma Drugs Res 1997, 13:39-44.

11. Azas N, Laurencin N, Delmas F, Di-Giorgio C, Gasquet M, Laget M, Timon-David P: Synergistic in vitro antimalarial activity of plant extracts used as traditional herbal remedies in Mali. Parasitol Res 2002, 88:165-171.

12. Otimenyin $\mathrm{SO}$, Uguru MO, Auta A: Anti-inflammatory and analgesic activities of Cassia goratensis and Sacrocephalus esculentus extracts. Journal of Herbs, Spices \& Medicinal Plants 2008, 13:59-67.

13. Etkin NL: The co-evolution of people, plants, and parasites: biological and cultural adaptations to malaria. Proc Nut Soc 2003, 62:311-317.

14. Tan RX, Zheng WF, Tang HQ: Biologically active substances from the genus Artemisia. Planta Med 1998, 64:295-302.

15. Elujoba AA, Odeleye OM, Ogunyemi CM: Traditional medical development for medical and dental primary healthcare delivery system in Africa. Afr J Tradit Complem 2005, 2:46-61.

16. Willcox M, Bodeker G, Rasoanaivo P: Traditional Medicinal Plants and Malaria. UK: CRC Press; 2004.

17. Clarkson C, Maharaj VJ, Crouch NR, Grace OM, Pillay P, Matsabisa MG: In vitro antiplasmodial activity of medicinal plants native to or naturalised in South Africa. J Ethnopharmacol 2004, 92:177-191.

18. Ali AN, Al-rahwi AK, Lindequist U: Some medicinal plants used in Yemeni herbal medicine to treat malaria. Afr J Tradit Complem 2004, 1:72-76.

19. Wright CW, Allen D, Cai Y, Chen ZP, Phillipson JD, Kirby GC, Warhurst DC, Tits M, Angenot L: Selective antiprotozoal activity of some Strychnos alkaloids. Phytother Res 1994, 8:149-152.

20. Gasquet M, Delmas F, Timon-David P, Keita A, Guindo M, Koita N, Diallo D, Doumbo O: Evaluation in vitro and in vivo of a traditional antimalarial drug, 'malarial 5'. Fitoterapia 1993, 64:423-426.

21. Elujoba AA: The role of pharmacognosy in phytotherapy, the challenges of our time. Nigerian Journal of Natural Products and Medicine 1998, 2:5-8.

22. WHO: Expert Committee on Malaria, 20th Report. Geneva: World Health Organization Technical Report Series; 2000:892.

23. Cheesbrough M: District laboratory practice manual in Tropical Countries pt 2. UK: Cambridge University Press; 2000:434.

24. WHO: Mefloquine therapy for Plasmodium falciparum malaria in children under 5 years of age in Malawi: in vivo/in vitro efficacy and correlation of drug concentration with parasitological outcome. Bull World Health Org 1990, 68:53-59.

25. Druilhe $P$, Moreno A, Blanc $C$, Brasseur $P$, Jacquier $P$ : Colorimetric in vitro drug sensitivity assay for $P$. falciparum based on a highly sensitive double- site pLDH antigen capture ELISA assay. Am J Trop Med Hyg 2001, 64:233-241.

26. Flores MVC, Berger-Eiszele SM, Stuart TS: Long-term cultivation of Plasmodium falciparum in media with commercial non-serum supplements. Parasitol Res 1997, 83:734-736.

27. Noedl $\mathrm{H}$ : Non linear evaluation of malaria drug sensitivity data (HN-NonLin V1.1). Bangkok, Thailand: Armed Forces Research Institute for Medical Sciences; 2002. http://www.meduniwien.ac.at/user/harald.noedl/malaria/ download.html.

28. WHO: In vitro micro-test (Mark III) for the assessment of P. falciparum to chloroquine, mefloquine, quinine, amodiaquine, sulfadoxine/pyrimethamine and artemisinin. Geneva, Switzerland: CTD/MAL/9720 Rev 2; 2001.

29. Happi CT, Gbotosho GO, Sowunmi A, Falade CO, Akinboye DO, Hudson T, Gerena L, Kyle DE, Milhous W, Wirth DF, Oduola AMJ: Molecular analysis of Plasmodium falciparum recrudescent malaria infections in children treated with chloroquine in Nigeria. Am J Trop Med Hyg 2004, 70:20-26.

30. Ogunfowokan O, Dankyau M, Madaki AJ, Thacher TD: Comparison of chlorproguanil-dapsone with a combination of sulfadoxinepyrimethamine and chloroquine in children with malaria in Northcentral Nigeria. Am J Trop Med Hyg 2009, 80:199-201.

31. Ibrahim ML, Gay-Andrieu F, Adehossi E, Lacroix V, Randrianarivelojosia M, Duchemin JB: Field-based evidence for the linkage of pfcrt and pfdhfr drug-resistant malaria genotypes and clinical profiles for severe malaria in Niger. Microbes Infect 2007, 9:599-604.
32. Talisuna AO, Staedke SG, D'Alessandro U: Pharmacovigilance of antimalarial treatment in Africa: is it possible? Malar J 2006, 5:50.

33. Pradines M, Mabika M, Parzy D, Owono MM, Lebeau C, Mourou MJR, Doury JC, Kombila M: In vitro susceptibility of African isolates of Plasmodium falciparum from Gabon to pyronaridine. Am J Trop Med Hyg 1999, 60:105-108.

34. Winkler S, Brandts C, Wernsdorfer WH, Graninger W, Bienzle U, Kremsner PG: Drug sensitivity of Plasmodium falciparum in Gabon: activity correlations between various antimalarials. Trop Med Parasitol 1994, 45:214-218.

35. Ashley AA, Stepniewska K, Lindegårdh N, McGready R, Hutagalung R, Singtoroj T, Hla G, Brockman A, Proux S, Wilahphaingern J, Singhasivanon P, White NJ, Nosten F: Pharmacokinetic study of artemether-lumefantrine given once daily for the treatment of uncomplicated multidrug-resistant falciparum malaria. Trop Med Int Health 2007, 12:201-208.

36. Sodiomon BS, Alfred BT, Adama G, Amidou D, Amidou O, Amadou TK Jean-Rene K, Morgan CC, Olliaro PL, Walter RJT: The efficacy and safety of a new fixed-dose combination of amodiaquine and artesunate in young African children with acute uncomplicated Plasmodium falciparum. Malar J 2009, 8:48.

37. WHO: Monitoring antimalarial drug resistance: a report of a consultation Geneva, Switzerland: WHO/CDS/CSR/EPH/2002.17. WHO/CDS/RBM/2002.39; 2003.

38. Alshawsh MA, Mothana RA, Al-Shamahy HA, Alsllami SF, Lindequist U: Assessment of antimalarial activity against Plasmodium falciparum and phytochemical screening of some Yemeni medicinal plants. Evid Based Complement Alternat Med 2009, 6:453-456. 10.1093/ecam/nem148.

39. Guido R, Menavanza N, Kurt H: Antifungal anthaquinones from Morinda lucida. Int J Pharmacol 1995, 33:107-114.

doi:10.1186/1475-2875-13-63

Cite this article as: Olasehinde et al:: In vitro studies on the sensitivity pattern of Plasmodium falciparum to anti-malarial drugs and local herbal extracts. Malaria Journal 2014 13:63.

\section{Submit your next manuscript to BioMed Central and take full advantage of:}

- Convenient online submission

- Thorough peer review

- No space constraints or color figure charges

- Immediate publication on acceptance

- Inclusion in PubMed, CAS, Scopus and Google Scholar

- Research which is freely available for redistribution 